\title{
La consulta popular en México. Una propuesta para el fortalecimiento de su diseño institucional a partir de experiencias normativas latinoamericanas
}

\author{
Public Consultation in Mexico. A Proposal \\ for Strengthening Institutional Design from \\ Latin American Regulatory Experiences
}

\begin{abstract}
A consulta popular no México. Uma proposta para fortalecer seu desenho institucional a partir de experiências regulatórias latino-americanas
\end{abstract}

Enoc Francisco Morán Torres* 


\section{Resumen}

El diseño institucional de consulta popular que prima en México representa un considerable avance normativo en la materia. Sin embargo, la complejidad de requisitos, la restricción en las materias de consulta y el interés del poder legislativo por privilegiar la decisión política sobre la petición de consulta dificultan su operacionalización y restringen la participación de la ciudadanía en los asuntos públicos del país, puesto que la única vía para que esta se dé continúa siendo el ejercicio del voto para efectos de la democracia representativa. En ese sentido, esta contribución académica analiza el diseño institucional mexicano de la consulta popular a fin de identificar aquellos aspectos que dificultan su ejercicio. Para ello, se parte de la revisión de la concepción del fenómeno de consulta popular y de las experiencias normativas que países latinoamericanos como Uruguay, Argentina, Colombia, Ecuador y Perú han configurado para regular este mecanismo de participación ciudadana. Ello permitirá aportar elementos que contribuyan al fortalecimiento de la consulta popular como mecanismo de democracia directa en México.

\section{Palabras clave}

Democracia; democracia directa; consulta popular; participación ciudadana. 


\section{Abstract}

The institutional design of public consultation prevailing in Mexico represents a considerable regulatory advance on the subject. However, the complex requirements, limited consultation matters, and the legislative branch's interest in privileging the political decision over the consultation request obstruct its operationalization and restrict citizens' participation in public affairs of the country. Then, the only way for it to occur continues to be the exercise of voting rights for representative democracy. This academic contribution analyzes the Mexican institutional design of public consultation to identify those aspects that obstruct its practice. It reviews the conception of public consultation and the regulatory experiences of Latin American countries, such as Uruguay, Argentina, Colombia, Ecuador, and Peru, in regulating this citizen participation process. As a result, it provides elements that contribute to strengthening public consultation as a direct democracy mechanism in Mexico.

\section{Keywords}

Democracy; direct democracy; public consultation; citizen participation. 


\section{Resumo}

O desenho institucional de consulta popular que ocorre no México representa um considerável avanço regulatória na matéria. Contudo, este, a partir da complexidade de requisitos, da restrição nas matérias de consulta e do poder legislativo por privilegiar a decisão política sobre a petição de consulta dificultam sua operacionalização e restringem a participação da cidadania nos assuntos públicos do país, visto que a única via para isso aconteça continua sendo o exercício do voto para efeitos da democracia representativa. Nesse sentido, esta contribuição acadêmica analisa o desenho institucional mexicano da consulta popular a fim de identificar os aspectos que dificultam seu exercício. Para isso, parte-se da revisão da concepção do fenômeno de consulta popular e das experiências regulatórias que países latino-americanos como Argentina, Colômbia, Equador, Peru e Uruguai vêm configurando para regularizar esse mecanismo de participação cidadã. Isso permitirá contribuir com elementos para fortalecer a consulta popular como mecanismo de democracia direta no México.

\section{Palavras-chave}

Democracia: democracia direta; consulta popular; participação cidadã. 
Sumario: Introducción. 1. La consulta popular desde la concepción mexicana. 2. Parámetros de consulta popular en América Latina. 2.1 Uruguay. 2.2. Colombia. 2.3. Argentina. 2.4. Ecuador. 2.5. Perú. 3. Propuesta para el fortalecimiento del diseño institucional para la consulta ciudadana en México. Conclusiones. Bibliografía.

En una buena ordenación de las cosas públicas, la masa es la que no actúa por sí misma. Tal es su misión. Ha venido al mundo para ser dirigida, influida, representada, organizada - hasta para dejar de ser masa o, por lo menos, aspirar a ello.

José Ortega y Gasset. ${ }^{1}$

\section{Introducción}

México cuenta con un diseño institucional de consulta popular que data del año 2014, que si bien representa un avance normativo importante a nivel constitucional y legal, considerando que anteriormente no se contaba con una Ley Federal de Consulta Popular, también posee diversas características que presentan una serie de restricciones al derecho de participación ciudadana ante la complejidad que implica el trámite administrativo previsto en el ordenamiento atinente.

En ese sentido, la presente contribución académica analiza el sistema mexicano respecto al diseño institucional del mecanismo de consulta popular previsto en la Constitución Política de los Estados Unidos Mexicanos y en la Ley Federal de Consulta Popular a partir de identificar como problema aquellas restricciones o limitaciones que el citado mecanismo posee y que dificultan la participación ciudadana a través de la consulta popular.

En virtud de lo anterior, para ofrecer una propuesta de fortalecimiento de la consulta popular en México resulta importante el análisis de su diseño institucional, soportado en la revisión de derecho extranjero a partir de la experiencia normativa en algunos países de América Latina.

Asimismo, para efectos de lo anterior, es pertinente señalar cómo se define la consulta popular y de qué manera la prevé su regulación constitucional y legal en México. Por lo que, en el presente artículo, se abordan una serie de disposiciones normativas que la sustentan como son aquellas derivadas de la Constitución Política de los Estados Unidos Mexicanos y de la Ley Federal de Consulta Popular.

Del mismo modo, se analizan algunos diseños institucionales dentro de América Latina: Uruguay, Colombia, Argentina, Ecuador y Perú, cuya regulación,

1 José Ortega y Gasset, La rebelión de las masas, 3 ed., México, Editorial Tomos, 2016, p. 108. 
principalmente del orden constitucional, permite advertir y contrastar las diferentes formas y procedimientos en que la consulta popular es regulada. Ello, con la finalidad de esbozar una propuesta para el fortalecimiento del diseño institucional de la consulta popular en México.

\section{La consulta popular desde la concepción mexicana}

La consulta popular representa uno de los mecanismos para ejercer la democracia directa. Su concepción y diseño se dan con la finalidad de fortalecer la participación del ciudadano en el ámbito público más allá de su excluyente intervención, reducida en muchos de los casos al acto volitivo de emisión del sufragio. No obstante, esta no es ajena a la democracia representativa, al contrario, como se ha sostenido con antelación, la democracia participativa fortalece la democracia representativa ${ }^{2}$ y permite contar con desarrollos democráticos más sólidos en los que el ciudadano es parte activa de los procesos de decisión.

En ese sentido, por rigor de método es importante abordar los conceptos de democracia y democracia directa, este último conducirá a la noción diversa de consulta popular, al ser la citada consulta uno de sus mecanismos y objeto de estudio de la presente aportación académica.

Para empezar, Antonio Camou, influenciado por Norberto Bobbio, refiere que la democracia es un conjunto de reglas fundamentales que establecen quién está autorizado a tomar decisiones, bajo qué procedimientos y en qué condiciones. Por lo que un gobierno será democrático si involucra a las personas en la toma de decisiones, está regido por la mayoría, y con la garantía de un conjunto de libertades básicas. ${ }^{3}$

Por su parte, Giovanni Sartori precisa que por democracia directa se entiende: “La democracia sin representantes y sin representación [...] Es también inmediatez de interacciones, una relación directa, cara a cara entre participantes. La democracia directa significa también gobernarse por sí mismos". ${ }^{4}$

Asimismo, Jean François Prud'homme aporta una definición de democracia directa en los términos siguientes:

La soberanía del pueblo no puede ser alienada, dado que el acto de delegación niega la esencia misma de la soberanía. El pueblo es libre en la medida en que no delega el ejercicio de su soberanía en asambleas legislativas. Más bien el pueblo

2 Enoc Francisco Morán Torres, Descifrando la partidocracia mexicana, México, Porrúa, 2017, passim.

3 Antonio Camou, "Gobernabilidad y democracia", Cuadernos de divulgación de la cultura democrática 6, 2 ed., 506 México, Instituto Nacional Electoral, 2019, pp. 71-72, en https://www.ine.mx/wp-content/uploads/2020/02/ cuaderno_06.pdf.

4 Giovanni Sartori, ¿Qué es la democracia?, México, Editorial Patria, trad. de Miguel Ángel González Rodríguez, 1993, pp. 78-79. 
reunido en asamblea, el que participa directamente en la ratificación de las leyes, las cuales deben ser aprobadas por unanimidad. ${ }^{5}$

Ahora bien, en lo que respecta a la consulta popular, Daniel Zovatto sostiene que esta puede ser obligatoria -dividida en automática y acotada- o facultativa -dividida en dos grupos: desde arriba y desde abajo-; sus resultados pueden o no ser vinculantes y a partir de la experiencia latinoamericana, dicho mecanismo se restringe con la exclusión de ciertas materias. ${ }^{6}$

Lo expuesto con antelación, evidentemente no se genera por dominio del concepto o decreto de la autoridad. De hecho, Michelangelo Bovero, siguiendo a Bobbio, apunta que el proceso democrático de participación en las decisiones públicas no puede desarrollarse sin la garantía de las libertades siguientes: 1) personal; 2) opinión y de prensa; 3) reunión; y 4) asociación. ${ }^{7}$ Así pues, para que la participación de la ciudadanía se dé, esta debe contar con la posibilidad plena de ejercer las libertades que le son inherentes a la persona en su condición de ciudadana.

Incluso, el sustento internacional se encuentra en la Convención Americana sobre Derechos Humanos (CADH) en el apartado de derechos políticos, instrumento que prevé que todos los ciudadanos deben gozar, entre otros, de la participación en la dirección de los asuntos públicos, directamente o por medio de representantes libremente elegidos. ${ }^{8}$ Asimismo, el Pacto Internacional de Derechos Civiles y Políticos (Pidesc) reconoce como derecho de los ciudadanos el participar en la dirección de los asuntos públicos por sí o a través de representantes. ${ }^{9}$

Ahora bien, tratándose de México, el instrumento de participación ciudadana en comento tiene base normativa de rango constitucional. Toda vez que la Constitución Política de los Estados Unidos Mexicanos primero reconoce como derecho y obligación de los ciudadanos el participar en las consultas populares sobre temas de trascendencia nacional o regional, después establece que se realizará el primer domingo del mes de agosto y, finalmente, acota que para que el resultado sea vinculante se exige una participación del $40 \%$ de los ciu-

5 Jean-François Prud'homme, "Consulta Popular y democracia directa”, Cuadernos de divulgación de la cultura democrática 15, 2 ed., México, Instituto Nacional Electoral, 2019, p. 29, en https://www.ine.mx/wp-content/ uploads/2020/02/cuaderno_15.pdf.

6 Daniel Zovatto, "Las instituciones de la democracia directa", en Alicia Lassidini et al. (comps.), Democracia en movimiento: mecanismos de democracia directa y participativa en América Latina, México, Universidad Nacional Autónoma de México, Centro de Investigaciones sobre Democracia Directa, Instituto Internacional para la Democracia y la Asistencia Electoral, 2014, pp. 16-20, en https://archivos.juridicas.unam.mx/www/bjv/libros/8/3717/3.pdf.

7 Michelangelo Bovero, Los adjetivos de la democracia, Conferencias Magistrales 2. Temas de la democracia, México, Instituto Nacional Electoral, 2016, p. 31, en https://www.ine.mx/wp-content/uploads/2019/04/CM_02_Bovero.pdf.

8 Artículo 23 de la Convención Americana sobre Derechos Humanos. Véase Organización de los Estados Americanos, Convención Americana sobre Derechos Humanos, en https://www.oas.org/dil/esp/tratados_b-32_convencion_americana_sobre_derechos_humanos.htm.

Artículo 25, primer párrafo, inciso a). 
dadanos inscritos en la lista nominal de electores. Sin embargo, restringe que no podrán ser objeto de esta: temas de la restricción de los derechos humanos y las garantías para su protección; los principios consagrados en el artículo 40 de la misma; la permanencia o continuidad en el cargo de los servidores públicos de elección popular; la materia electoral; el sistema financiero, ingresos, gastos y el Presupuesto de Egresos de la Federación; las obras de infraestructura en ejecución; la seguridad nacional y la organización, funcionamiento y la disciplina de la Fuerza Armada permanente. ${ }^{10}$

Por su parte, la Ley Federal de Consulta Popular producto de la reforma constitucional en materia político-electoral, publicada en el Diario Oficial de la Federación el 10 de febrero de 2014, establece que el multirreferido instrumento es el mecanismo de participación por el cual los ciudadanos ejercen su derecho, a través del voto emitido mediante el cual expresan su opinión respecto de uno o varios temas de trascendencia nacional. ${ }^{11}$

Así las cosas, el citado ordenamiento federal prevé quiénes pueden solicitar una consulta popular, esto es: el presidente de la República; el equivalente al $33 \%$ de los integrantes de cualquiera de las Cámaras del Congreso o los ciudadanos en un número equivalente, al menos, al $2 \%$ de los inscritos en la lista nominal de electores para el caso de consulta de trascendencia nacional y para el caso de consultas populares con temas de trascendencia regional competencia de la Federación, los ciudadanos de una o más entidades federativas en un número equivalente al $2 \%$ de los inscritos en la lista nominal de electores de la entidad o entidades federativas que correspondan. ${ }^{12}$

En efecto, la solicitud de una consulta popular debe tener, por lo menos, los requisitos siguientes: 1 ) nombre completo y firma del solicitante o solicitantes, 2) el propósito de la consulta y los argumentos por los cuales el tema se considera de trascendencia nacional, y 3) la pregunta que se proponga para la consulta deberá ser elaborada sin contenidos tendenciosos o juicios de valor y formulada de tal manera que produzca una respuesta categórica en sentido positivo o negativo; y estar relacionada con el tema de la consulta. Solo se podrá formular una pregunta en la petición de consulta popular. ${ }^{13}$

10 Artículo 35, párrafos VIII y 36, fracción III de la Constitución Política de los Estados Unidos Mexicanos, considerando la reforma del 20 de diciembre de 2019 a diversas disposiciones del numeral 35 en cita. Véase Cámara de Diputados, Constitución Política de los Estados Unidos Mexicanos, en http://www.diputados.gob.mx/ LeyesBiblio/index.htm.

11 Artículo 4 de la Ley Federal de Consulta Popular. Véase Cámara de Diputados, Ley Federal de Consulta Popular, en http://www.diputados.gob.mx/LeyesBiblio/pdf/LFCPo.pdf.

12 De conformidad con el Instituto Nacional Electoral, la Lista Nominal Electoral, al 27 de marzo de 2020, se conformaba de 90’036.367 ciudadanas y ciudadanos. Véase Instituto Nacional Electoral, Estadísticas del padrón

508 electoral y lista nominal de electores, en https://listanominal.ine.mx/ESTADISTICAS/index.php. la solicitud de $1^{`} 800.727,34$ ciudadanas y ciudadanos para activar el proceso previsto en el citado ordenamiento. Ley Federal, cit., nota 12, artículo 21. 
También, cuando se trate de solicitud proveniente de los legisladores federales, además de lo establecido con antelación, deberá acompañarse del anexo que contenga nombres completos y firmas de por lo menos el $33 \%$ de los integrantes de cualquiera de las cámaras del Congreso, ${ }^{14} \mathrm{y}$ se designará como representante a uno de los legisladores promotores. ${ }^{15}$

Asimismo, cuando los ciudadanos sean quienes promueven, además de los requisitos ya mencionados, se deben incluir los siguientes: nombre completo y domicilio del representante y anexo que contenga los nombres completos de los ciudadanos y su firma, además de la clave de elector y el número identificador al reverso de la credencial de elector derivado del reconocimiento óptico de caracteres (OCR) de la credencial para votar con fotografía vigente $^{16}$ expedida por el otrora Instituto Federal Electoral o el Instituto Nacional Electoral, en su caso. ${ }^{17}$

Además, la legislación de mérito exige que toda la documentación, así como los anexos, deberán estar plenamente identificados, señalando en la parte superior de cada hoja la referencia al tema de trascendencia nacional que se propone someter a consulta popular. ${ }^{18}$ Aspectos eminentemente formales que, si bien no abonan a la sustancia, sí contribuyen a la certeza del procedimiento.

De lo expuesto hasta el momento se advierte que en lo relativo a la consulta popular intervienen los poderes Ejecutivo y Legislativo, en cuanto a la solicitud de su inicio. No obstante, bajo el diseño institucional en estudio, quien se encarga de resolver acerca de la constitucionalidad de las consultas populares es la Suprema Corte de Justicia de la Nación, mientras que el Instituto Nacional Electoral es el encargado de la organización, el desarrollo, el cómputo y los resultados del referido mecanismo de participación ciudadana.

Ahora bien, una vez revisada la estructura normativa de la figura de consulta popular en México, no se puede soslayar que, a pesar de la complejidad de su diseño procedimental normativo, esta debe tener un papel más importante que el que le ha sido adjudicado con las disposiciones normativas en comento. De hecho, su previsión legislativa en mayo de 2014 derivó de una pregonada reforma constitucional en materia política-electoral, producto de un acuerdo entre élites partidocráticas que resultó en un diseño institucional inaccesible para la ciudadanía. Ello, no obstante que existía una añeja aspiración de diversos sectores de la sociedad quienes, emulando la tradición latinoamerica-

14 En el caso mexicano, el Congreso se conforma de dos Cámaras: diputados, integrada por 500 legisladores, y senadores por 128 parlamentarios.

15 Ley Federal, cit., nota 12, artículo 22

16 Ibid., artículo 23.

17 Con la reforma constitucional en materia política-electoral, publicada en el Diario Oficial de la Federación el 10 de febrero de 2014, el Instituto Federal Electoral cambió su denominación a Instituto Nacional Electoral. 
na, pretendieron sin mayor éxito, desde abajo, impulsar cambios legislativos para incorporar más instrumentos de democracia directa no como paliativos democráticos, sino como instrumentos eficaces para contribuir al fortalecimiento de la democracia.

No obstante, la dificultad material para cumplir con los requisitos legales de procedibilidad establecidos, entre los que se encuentra la materia de la consulta, la constitucionalidad de las preguntas y el número de ciudadanos que, de ser el caso, deben respaldar la iniciativa, tornan en la práctica inviable su ejecución y contribuyen aún más al desánimo de los ciudadanos de participar en instrumentos de democracia directa, lo que restringe su participación al mero acto de emisión del voto para elegir representantes. Es decir, la barrera procedimental-administrativa impide que la participación activa de los ciudadanos se materialice, lo que Habermas denominaba como acción comunicativa. ${ }^{19}$

Al caso, basta con recordar los tres pronunciamientos de la Suprema Corte de Justicia de la Nación ${ }^{20}$ relativos a la constitucionalidad de la materia de diversas consultas populares, convocadas por el Congreso de la Unión que le fueron presentadas en el año 2014 y que marcaron un hito en la historia constitucional moderna de México. En la primera de ellas: 2/2014, el Pleno se pronunció respecto de la calificación de la constitucionalidad de la materia de consulta que se planteó bajo la pregunta siguiente: “¿Estás de acuerdo en que la Ley Federal del Trabajo establezca que la Comisión Nacional de los Salarios Mínimos fije un nuevo salario mínimo que cubra todas las necesidades de una familia para garantizar al menos la línea de bienestar determinada por el Coneval?", y determinó su inconstitucionalidad en virtud de que esta, según razonó el Alto Tribunal, se refería a los ingresos y gastos del Estado y restringía el derecho humano social de los trabajadores, reconocido en la Carta Magna. ${ }^{21}$

En lo que respecta a la segunda: 3/2014, el Tribunal Pleno, al revisar la constitucionalidad de la pregunta: ¿Está de acuerdo en que se mantengan las reformas a los artículos 25, 27 y 28 de la Constitución en materia energética? concluyó que el objeto de la consulta era inconstitucional en virtud de que, al estar formulada en términos integrales respecto de todas las previsiones constitucionales en materia energética, su desahogo incidiría en la vigen-

19 Jürgen Habermas, Teoría de la acción comunicativa I, 4 ed., Bogotá, Taurus, 1999, passim, en https://zoonpolitikonmx.files.wordpress.com/2014/03/habermas-jurgen-teoria-de-la-accion-comunicativa-i.pdf.

20 No pasa desapercibida la Consulta a Trámite 1/2014, resuelta el 27 de marzo de 2014 en la que el Pleno de la Suprema Corte de Justicia de la Nación determinó su improcedencia y desechó de plano la solicitud presentada con motivo de la revisión de la constitucionalidad de la materia de la consulta popular relativa a la modificación de los artículos 27 y 28 de la Constitución Política de los Estados Unidos Mexicanos en materia energética. Véase Suprema Corte de Justicia de la Nación, Consulta a trámite prevista en el párrafo segundo de la fracción II del artículo 14 de la Ley Orgánica del Poder Judicial de la Federación 1/2014, 27 de marzo de 2014, en http://www2.scjn.gob.mx/ConsultaTematica/PaginasPub/DetallePub.aspx?AsuntoID=161925.

21 Suprema Corte de Justicia de la Nación, Revisión de constitucionalidad de la materia de Consulta Popular 2/2014, 29 de octubre de 2014, en http://www2.scjn.gob.mx/ConsultaTematica/PaginasPub/DetallePub. aspx?AsuntoID=172299. 
cia de determinadas disposiciones constitucionales que regulan el origen y destino de los recursos derivados de los ingresos de la industria petrolera. ${ }^{22}$

En lo que corresponde a la tercera: 4/2014, el Pleno de la Suprema Corte de Justicia de la Nación revisó la constitucionalidad de la siguiente pregunta: ¿Estás de acuerdo en que se modifique la Constitución para que se eliminen 100 de las 200 diputaciones federales plurinominales y las 32 senadurías plurinominales?, y arribó a la conclusión de la inconstitucionalidad de la materia de la consulta popular porque se refería a un asunto electoral. ${ }^{23}$

Las resoluciones citadas supra evidencian la complejidad del entramado normativo que dificulta la operacionalización de la consulta popular regulada en la legislación mexicana. De hecho, en los casos de mérito, a pesar de que implicaban tres asuntos de interés popular, más allá de quienes las impulsaron y los fines mediáticos o políticos que perseguían: reforma energética, salarios mínimos y reducción de diputados plurinominales, dichos temas encuadraban en los supuestos de improcedencia previstos en la Constitución Política de los Estados Unidos Mexicanos y en la Ley Federal de Consulta Popular. Por lo que, con base en ello, la Suprema Corte de Justicia de la Nación, en un acto de control de constitucionalidad, determinó la inconstitucionalidad de las preguntas planteadas.

Además, considerando que la situación de la democracia directa en México es aún precaria, el diseño institucional de la consulta popular debiera permitir que esta se convierta en un mecanismo eficaz para tomar en cuenta a la población respecto de aquellos temas del ámbito público que tengan un impacto colectivo a partir de la generación de las condiciones que coadyuven a su ejercicio óptimo. Aspecto nada sencillo puesto que para que ello ocurra, aún se requiere la voluntad política de aquellos que detentan el poder político y ven, en la democracia directa, una forma de debilitamiento de la democracia representativa o, lo que es aún más peligroso, la forma de acotar el poder que detentan y ejercen sin mayores controles.

Respecto a este mecanismo, Jean-François Prud'homme considera lo siguiente:

El argumento según el cual la democracia directa debilita a las instituciones representativas puede ser utilizado tanto en favor como en contra de los mecanismos de consulta directa. En efecto, la mera posibilidad de recurrir a tales procedimientos

22 Suprema Corte de Justicia de la Nación, Revisión de constitucionalidad de la materia de Consulta Popular 3/2014, 30 de octubre de 2014, en http://www2.scjn.gob.mx/ConsultaTematica/PaginasPub/DetallePub. aspx?AsuntoID $=172300$.

23 Suprema Corte de Justicia de la Nación, Revisión de constitucionalidad de la materia de Consulta Popular 4/2014, 3 de noviembre de 2014, en http://www2.scjn.gob.mx/ConsultaTematica/PaginasPub/DetallePub. aspx?AsuntoID=172628. 
puede constituir un incentivo para mejorar los procesos legislativos de la democracia representativa. ${ }^{24}$

No obstante lo anterior, es tal el nivel de desconocimiento sobre su concepto y alcances que, en aras de ejercer lo que denominan en el lenguaje común como consulta popular, se realizan actos de simulación que han tenido como efecto útil la legitimación política de la toma de decisiones. Ello, a pesar de carecer de legitimidad democrática y de que su carácter vinculante sigue sujeto a la voluntad de quien, detentando el poder, decide qué temas y bajo qué procedimientos se llevará a cabo lo que denominan como consulta popular y quiénes asistirán al acto en el que se solicitará la manifestación de voluntad. Lo expuesto evidencia la necesidad de contar con un diseño institucional que permita la operacionalización de la consulta popular como mecanismo de democracia directa y eficaz para impulsar la participación ciudadana en el ámbito público a partir de conocer su opinión sobre asuntos que impacten a la colectividad, motivo por el cual, en líneas subsiguientes, se revisará en el derecho extranjero cómo se regula el instrumento en comento, particularmente en las disposiciones constitucionales y legales de países latinoamericanos como Uruguay, Argentina, Colombia, Ecuador y Perú, cuyos resultados en el desarrollo democrático son a la vez contrastantes.

\section{Parámetros de consulta popular en América Latina}

En la mayoría de los países de América Latina, hablar de democracia directa implica referirse a un abordaje de mayor antigüedad que en el caso de México. Su historia institucional, en muchos de los casos, es el resultado de la lucha social y del impulso, desde abajo, para la conquista de los derechos. En particular, los mecanismos de democracia directa, en la teoría y en la práctica, reportan una basta experiencia. Por este motivo es pertinente analizar el andamiaje normativo con el que cuentan diversos países de la citada región continental con relación a la regulación de la consulta popular como mecanismo de democracia directa.

De manera que, por rigor de método, la revisión realizada en diferentes países que conforman América Latina se lleva a cabo como un ejercicio de estudio de derecho extranjero con el objeto de identificar semejanzas y diferencias con relación a la previsión normativa mexicana. Puesto que, en términos de Lucio Pegoraro, el examen comparado del derecho sigue la fase del conocimiento del derecho extranjero y se concreta en la comparación con otro derecho con el objetivo de observar las semejanzas y las diferencias (y derivar las posteriores consecuencias). ${ }^{25}$ Sin embargo, ello no implica un ejercicio de derecho comparado.

24 Prud'Homme, "Consulta Popular y democracia directa”, op. cit., p. 86.

25 Cfr. Lucio Pegoraro, "El método comparativo. Un shortcut para comprender el mundo", en Lucio Pegoraro y Angelo Rinella (dirs.), Derecho Constitucional Comparado, t. 2, vol. A, Argentina, Astrea, 2018, pp. 9-10. 
Además, se utilizarán como referente los datos que contiene el Índice para el Desarrollo Democrático para América Latina que impulsa la Fundación Konrad Adenauer en virtud de que los parámetros del citado índice se aplican a los diferentes países latinoamericanos y permiten advertir, bajo indicadores de medición similares, cuál es nivel de desarrollo democrático que presentan en dimensiones como: democracia de los ciudadanos, democracia de las instituciones, democracia social y democracia económica, además de invocar los datos aportados por Latinobarómetro en su última edición, que data del año 2018, con la finalidad de identificar el nivel de satisfacción de los ciudadanos respecto de la democracia. Sin embargo, en algunas ocasiones, el nivel de desarrollo democrático y el porcentaje de ciudadanos que proyectan un determinado grado de satisfacción con la democracia que evidencian los países contrasta con el avance o la deficiencia en la regulación normativa del instrumento de participación ciudadana objeto de estudio, la consulta popular.

Asimismo, para efectos de identificar en las disposiciones normativas, principalmente del orden constitucional, que se abordará el concepto en estudio, se utilizará la aportación doctrinal que propone Daniel Zovatto, dado que es un referente académico en la materia, en el sentido de que consulta popular, plebiscito o referéndum son términos que se utilizan indistintamente en América Latina. ${ }^{26}$

En virtud de lo anterior, la revisión de las disposiciones normativas en los países señalados se realizará a partir de diversos parámetros que servirán de base para el análisis y la comprensión de dichas instituciones de democracia directa, a saber: nombre de la figura concreta, fuente constitucional, requisitos de procedibilidad, procedimiento y si cuentan o no con el carácter de vinculantes.

\subsection{Uruguay}

La República Oriental del Uruguay, es uno de los países con mayor desarrollo democrático, y ocupa el segundo lugar de América Latina. ${ }^{27}$ De hecho, ha sido de los primeros en Latinoamérica en incorporar los instrumentos de democracia directa. Respecto del caso de estudio, Uruguay en su Constitución contempla dos tipos de instrumentos de participación ciudadana: iniciativa y referéndum. Sin embargo, para efectos del presente trabajo, se analizará, en

Para Lerner todo jurista compara la vieja jurisprudencia con la nueva, los hechos con el derecho, el texto de la ley con la interpretación que tal o cual tribunal le ha dado, soluciones o posturas de distintos autores. Pero esto no es derecho comparado. Véase Pablo Lerner, "Sobre armonización, derecho comparado y la relación entre ambos", en Boletín Mexicano de Derecho Comparado XXXVII (111) (2004), pp. 960-961, en https://revistas. juridicas.unam.mx/index.php/derecho-comparado/article/view/3807.

26 Zovatto, "Las instituciones de la democracia directa", op. cit., p. 16.

27 Konrad Adenauer Stiftung (KAS), Índice de Desarrollo Democrático de América Latina 2016, Uruguay, Fundación Konrad Adenauer Argentina, Polilat, 2016, pp. 13-14, http://idd-lat.org/2016/downloads/idd-lat-2016. pdf?nocache $=7687652837$. 
términos de Daniel Zovatto, la forma jurídica de consulta popular conocida como referéndum. ${ }^{28}$

La Constitución de la República Oriental del Uruguay, en su sección IV, respecto a la forma de gobierno y sus diferentes poderes, establece que la nación adopta para su Gobierno la forma democrática republicana. Su soberanía será ejercida directamente por el Cuerpo Electoral en los casos de elección, iniciativa y referéndum, e indirectamente por los poderes representativos que establece esa Constitución; todo conforme a las reglas expresadas en esta..$^{29}$ Además, el citado ordenamiento constitucional, en su numeral 304, precisa que la ley reglamentará el referéndum como recurso contra los decretos de Juntas Departamentales. Para ello, se requerirá la mayoría absoluta de votos del total de miembros de cada Cámara.

En dicha Constitución, en su artículo 322, también se señala que será la Corte Electoral quien conocerá de todos los actos y procedimientos electorales, decidirá en última instancia sobre las apelaciones y los reclamos que produzcan, y será juez de las elecciones para cargos electivos, actos de plebiscito y referéndum. Asimismo, menciona que, si el plebiscito fuera afirmativo por resolución firme de la Corte Electoral, la reforma entrará en vigor obligatoriamente a partir de ese momento, esto último sería el sustento de su vinculación.

A nivel nacional, la misma Constitución menciona que esta podrá ser reformada total o parcialmente y uno de los procedimientos por los cuales se puede realizar es por medio de la iniciativa popular ${ }^{30}$. Sin embargo, cuando la Asamblea General formule proyectos sustitutivos, someterá a decisión popular en la elección inmediata posterior tales proyectos. Similar suerte correrán los proyectos de reforma que reúnan dos quintos del total de componentes de la Asamblea General.

En el mismo artículo se señala que se tienen que reunir dos quintos del total de componentes de la Asamblea General para que se realice. Sin embargo, para que sea afirmativo dicho instrumento se requerirá que la mayoría absoluta de los ciudadanos que concurran a los comicios vote "SÍ", y deberá representar, por lo menos, el $35 \%$ del total de inscritos en el Registro Cívico Nacional.

Incluso, quienes pueden presentar proyectos tratándose de la reforma de la Constitución son los senadores, los representantes y el Poder Ejecutivo para posteriormente poder aprobar la iniciativa por parte de la Asamblea General. y revocatoria de mandato. Véase Zovatto, "Las instituciones de la democracia directa", op. cit., p. 14.

29 Artículo 82, Constitución de la República Oriental del Uruguay. Véase Poder Legislativo de la República Oriental del Uruguay, Constitución de la República, en https://parlamento.gub.uy/documentosyleyes/constitucion. 
De igual forma, también el $25 \%$ del total de inscritos habilitados para votar podrá interponer, dentro del año de su promulgación, el recurso de referéndum contra las leyes y ejercer el derecho de iniciativa ante el Poder Legislativo, según el artículo 79 de la citada Constitución.

En este sentido, como los anteriores artículos lo prevén, para que este mecanismo surta efecto debe ser aprobado por la mayoría absoluta tanto de las cámaras departamentales como de la Asamblea General, cuando se trata de reformas a la Constitución en comento.

Lo expuesto con antelación permite advertir la importancia que la Constitución de la República Oriental del Uruguay les da a los instrumentos de participación ciudadana, sometiendo decisiones importantes -como son las reformas constitucionales- a la consideración de la ciudadanía y otorgando a la Corte Electoral la facultad de intervención judicial en los casos de plebiscito y referéndum. Ello, en consistencia con el liderazgo que posee en calidad institucional y eficiencia política que le da el IDD-lat 2016. ${ }^{31}$

\subsection{Colombia}

Este país ocupa el lugar trece en el ranking del IDD-lat 2016, ${ }^{32}$ tiene un instrumento de democracia directa, al cual se le conoce con el nombre de consulta popular, está fundamentado en la Constitución Política, ordenamiento que lo considera como un mecanismo de participación del pueblo en ejercicio de su soberanía, así como también en la Ley 134 de 1994 que regula los mecanismos de participación ciudadana en la República de Colombia. ${ }^{33}$

En efecto, dentro de la Constitución Política de Colombia, en el apartado de participación democrática y de los partidos políticos, específicamente en el capítulo de las formas de participación democrática, se señala que son mecanismos de participación del pueblo en ejercicio de su soberanía: el voto, el plebiscito, el referendo, la consulta popular, el cabildo abierto, la iniciativa legislativa y la revocatoria del mandato. ${ }^{34}$ Menciona también en su artículo 104 constitucional que el presidente de la República, con la firma de todos los ministros y previo concepto favorable del Senado, ${ }^{35}$ podrá consultar al pueblo decisiones de trascendencia nacional. La decisión del pueblo será obligatoria, por lo que esta se torna vinculante.

KAS, "El método comparativo. Un shortcut para comprender el mundo", op. cit., p. 211.

Ibid., p. 14.

33 Instituto Interamericano de Derechos Humanos, Ley 134 de 1994 (mayo 31) por la cual se dictan normas sobre mecanismos de participación ciudadana, en https://www.iidh.ed.cr/capel2016/media/1111/ley-134-1994-mecanismos-de-participaci\%C3\%B3n-ciudadana.pdf.

34 Artículo 103, Constitución Política de Colombia. Véase Corte Constitucional de la República de Colombia, Constitución Política de Colombia 1991, en https://www.corteconstitucional.gov.co/inicio/Constitucion\%20politica $\% 20$ de $\% 20$ Colombia.pdf.

35 De Conformidad con el artículo 171 de la Constitución Colombiana, el Senado de la República se conforma de 100 miembros y un número adicional de 2 senadores elegidos por comunidades indígenas. 
Asimismo, el texto constitucional colombiano prevé una consulta popular dentro de los distintos departamentos en la cual los gobernadores y alcaldes, según el caso, podrán realizar consultas populares para decidir sobre asuntos de competencia del respectivo departamento o municipio.

De hecho, en Colombia también los movimientos y partidos políticos son quienes tienen la posibilidad de celebrar consultas populares que coincidan o no con las elecciones a corporaciones públicas. ${ }^{36}$ Dichas consultas pueden ser organizadas por los institutos políticos para la toma de sus decisiones o la selección de candidatos, y será el Consejo Nacional Electoral (CNE) el facultado para colaborar en la realización de dichas consultas. ${ }^{37}$

Aunado a lo anterior, en Colombia será la Corte Constitucional quien decida sobre la constitucionalidad cuando esta revise el cumplimiento de los requisitos que la Constitución colombiana prevé para la realización de los actos legislativos, la convocatoria a referendo, a la consulta popular o el acto de convocación a la Asamblea Constituyente. ${ }^{38}$

Por su parte, la Ley 134 de 1994 es el instrumento normativo que regula los mecanismos de participación ciudadana, a saber: iniciativa popular legislativa y normativa; el referendo; la consulta popular del orden nacional, departamental, distrital, municipal y local; la revocatoria del mandato; el plebiscito; y el cabildo abierto. ${ }^{39}$

El citado ordenamiento legal define a la consulta popular de la forma siguiente:

La consulta popular es la institución mediante la cual, una pregunta de carácter general sobre un asunto de trascendencia nacional, departamental, municipal, distrital o local es sometida por el presidente de la República, el gobernador o el alcalde, según el caso, a consideración del pueblo para que este se pronuncie formalmente al respecto. En todos los casos, la decisión del pueblo es obligatoria. Cuando la consulta se refiera a la conveniencia de convocar una asamblea constituyente, las preguntas serán sometidas a consideración popular mediante ley aprobada por el Congreso de la República. ${ }^{40}$

Asimismo, regula que se puede someter a consulta si cumple con las siguientes condiciones: que sea de competencia del respectivo mandatario. El presidente solo podrá tratar asuntos de carácter nacional, los gobernadores asuntos departamentales y alcaldes municipales los asuntos que competen a su demarcación. Tampoco podrán ser objeto proyectos de articulado ni la convocatoria

Constitución Política de Colombia, cit., nota 35, artículo 107. Ibid., artículo 265.1 .

Ibid., artículo 379.

51639 Artículo 1 de la Ley 134 de 1994. Véase Congreso de Colombia, Ley 134 de 1994 por la cual se dictan normas sobre Mecanismos de Participación Ciudadana, en https://www.iidh.ed.cr/capel2016/media/1111/ley134-1994-mecanismos-de-participaci\%C3\%B3n-ciudadana.pdf. 
a una asamblea constituyente. ${ }^{41}$ Incluso, precisa que la redacción de las preguntas que se someterán a consulta debe ser clara y dicotómica. Es decir, que se puedan responder con un Sí o un No. De hecho, el presidente de la República deberá enviar al Senado, para su aceptación, el texto de las preguntas, la justificación y fecha de la consulta popular, ${ }^{42}$ misma que deberá realizarse dentro de los cuatro meses posteriores a la aceptación emitida por el Senado. ${ }^{43}$

De la misma manera, se destaca una característica de la legislación colombiana, al precisar que al someter al pueblo el tema de la consulta popular, esta no podrá concurrir con otro tipo de elección y no podrá realizar consultas sobre temas que impliquen modificaciones a la Constitución. ${ }^{44}$ También, como se apuntó supra, la decisión es vinculante cuando la haya votado en el mismo sentido más del $50 \%$ más uno de los votos válidos emitidos y que hayan participado no menos de la tercera parte de los ciudadanos incorporados en el censo electoral. ${ }^{45}$

Además, la legislación en estudio admite la actuación de la sociedad civil en el marco de la participación democrática, reconociéndole el derecho de participar, a través de las veedurías ciudadanas, como vigilante de la función pública y en aquellos ámbitos en los que de forma parcial o total se ejerzan recursos públicos. ${ }^{46}$ También, establece la obligación presupuestal de prever dichos recursos para la realización de los mecanismos de participación ciudadana previstos en la citada Ley. ${ }^{47}$

De ahí que, la legislación colombiana aporta aspectos relevantes para el objeto de estudio de la presente contribución académica: la amplia gama de posibilidades o ámbitos en los que la consulta popular puede operar; la previsión presupuestal para su ejecución; la corta temporalidad -4 meses- para su ejecución a partir de su aprobación correspondiente; la participación individual o de la sociedad civil en los procesos de participación democrática; la participación del poder del Estado -el Ejecutivo propone, el Legislativo aprueba y el Judicial revisa la constitucionalidad del cumplimiento de requisitos- en el proceso de consulta y la no concurrencia de la consulta con un proceso comicial.

Ahora bien, no obstante los aspectos relevantes que presenta a nivel normativo la regulación de la figura de consulta popular, Colombia, de conformidad con el IDD-lat 2016, evidencia un descenso en democracia de los ciudadanos y en desarrollo económico, y se posiciona entre el grupo de países con mínimo desarrollo democrático en América Latina. Sin embargo, también presenta una

Ibid., artículo 52.

Ibid., artículo 53. En el caso de las propuestas de consulta presentadas por el gobernador o alcalde al consejo o a la junta administradora local, el tribunal contencioso-administrativo se pronunciará sobre su constitucionalidad. Ibid., artículo 54 .

Ibid., artículo 50 .

Ibid., artículo 55.

Ibid., artículos 99-100.

Ibid., artículo 105. 
leve mejoría en calidad de las instituciones. ${ }^{48}$ Incluso considerando los datos aportados por Latinobarómetro, Colombia se encuentra en el primer lugar de los países cuyos ciudadanos consideran que la democracia, aún con todos sus problemas, es la mejor forma de gobierno. ${ }^{49}$

\subsection{Argentina}

Argentina ocupa el octavo lugar en el ranking de IDD lat $2016^{50}$ con relación al resto de países latinoamericanos y, según datos de Latinobarómetro 2018, ocupa el sexto lugar de los países de América Latina que consideran a la democracia, a pesar de sus problemas, como el mejor sistema de gobierno. Ello, no obstante que también ocupa el segundo lugar de los países de la región cuyos ciudadanos consideran que su democracia tiene grandes problemas. ${ }^{51}$

En la Constitución de la nación Argentina se prevé que el Congreso, a iniciativa de la Cámara de Diputados, podrá someter un proyecto de ley a consulta popular, cuyo resultado afirmativo lo convertirá en ley y su promulgación será automática. Además, el presidente o el Congreso de la Nación podrá convocar a consulta popular no vinculante por lo que la emisión del voto no es obligatoria. ${ }^{52}$

Por su parte, la Ley 25.432, promulgada el 21 de junio de 2001, distingue entre la consulta popular vinculante y no vinculante. Respecto de la primera, establece que el Congreso de la nación ${ }^{53}$ podrá someter a consulta vinculante todo proyecto de ley. ${ }^{54}$ Para ello, en sesión especial, deberá contar con la mayoría absoluta de los miembros presentes en cada una de las Cámaras, ${ }^{55}$ cuyo voto del electorado resulta obligatorio. ${ }^{56}$ En lo que respecta a la validez del resultado de la consulta, se requiere la participación de, al menos, el $35 \%$ de los electores inscritos ${ }^{57}$ en el Padrón Electoral Nacional. ${ }^{58}$

$48 \quad$ KAS, Índice de Desarrollo Democrático de América Latina 2016, op. cit., pp. 103-106.

49 Corporación Latinobarómetro, Informe 2018, Santiago de Chile, 2018, p. 31, en https://www.latinobarometro. org/lat.jsp.

$50 \quad$ KAS, Índice de Desarrollo Democrático de América Latina 2016, op. cit., p. 66.

51 Corporación Latinobarómetro, Informe 2018, op. cit., pp. 31-34.

52 Artículo 39, Constitución Nacional de la Nación Argentina. Véase Congreso de la Nación Argentina, Constitución Nacional, en https://www.congreso.gob.ar/constitucionNacional.php.

53 En términos del artículo 44 de la Constitución Nacional de la Nación Argentina, el Congreso de la Nación está conformado por una Cámara de Diputados de la Nación y otra de Senadores de las Provincias y Ciudad de Buenos Aires.

54 Artículo 1 de la Ley 25.432. Véase Congreso de la Nación Argentina, Ley 25.432 Consulta popular vinculante y no vinculante, en https://www.argentina.gob.ar/normativa/nacional/ley-25432-67518/actualizacion.

55 Ibid., artículos 2-3.

56 El artículo 12 del Código Electoral Nacional establece como deber del elector el votar en las elecciones nacionales que se realicen en su distrito. Por su parte, el artículo 1 del citado ordenamiento define a los electores como aquellos argentinos por nacimiento desde los 16 años y por naturalización desde los 18 años. Véase Cámara de Diputados, Ley 19945, Código Electoral Nacional, en https://www.diputados.gov.ar/export/hcdn/

51857 Artículo 4 de_la Ley 25.432, Consulta popular vinculante y no vinculante, cit.

58 El artículo 29 del Código Electoral Nacional, en lo relativo al Padrón Nacional Electoral, determina lo siguiente: los padrones provisorios depurados constituirán el padrón electoral definitivo destinado a las elecciones 
Del mismo modo, es destacable que el citado ordenamiento legal regule que, una vez aprobada por la mayoría, tal como lo prevé la Constitución de la Nación Argentina en su artículo 39, se convierta automáticamente en Ley y deberá publicarse en el Boletín Oficial de la República Argentina en el plazo de diez días hábiles posteriores a la proclamación de resultados.

A todo esto, en lo que corresponde a la consulta popular no vinculante prevista en el Título II de la Ley en estudio, esta podrá invocarse con las excepciones previstas en el mismo ordenamiento, en torno a cualquier asunto de interés de la nación cuya emisión del voto no resulta obligatoria. ${ }^{59} \mathrm{Su}$ convocatoria la realiza el presidente de la República Argentina o cualquiera de las Cámaras del Congreso de la Nación, y cuando su resultado implique la aprobación de la mayoría de votantes, el efecto será su incorporación a la agenda legislativa de la Cámara de Diputados de la Nación. ${ }^{60}$

Más aún, en ambos casos, es decir vinculante o no vinculante, la pregunta planteada en la consulta popular tendrá una estructura que permita la respuesta dicotómica. Cuando se trate de un proyecto de ley, este deberá presentarse de manera íntegra. Asimismo, la convocatoria a consulta deberá publicarse en el Boletín Oficial de la República y en dos periódicos de mayor circulación en el país y en el de mayor circulación en cada una de las provincias. ${ }^{61}$ Ello, con la finalidad de que los ciudadanos conozcan el proyecto o la pregunta, y cuenten los elementos necesarios que les permitan participar en la consulta y emitir su voto a favor o en contra de la propuesta presentada.

Además, se permite la participación de los partidos políticos en el proceso de socialización de la materia de consulta y para fijar postura sobre ello, considerando el plazo de 60 a 120 días para la realización de la consulta, contados a partir de su publicación. Incluso, se norma la participación de la Justicia Nacional Electoral en lo relativo a los comicios, cuya validez del resultado será a partir de los votos válidos, ${ }^{62}$ y la previsión de un presupuesto público para su ejecución. ${ }^{63}$

En consecuencia, de las disposiciones constitucionales y legislativas argentinas se destaca la participación de los partidos políticos en el proceso de difusión e información sobre la consulta; la difusión del proyecto de ley o pregunta para los electores tanto en medio oficial como no oficial de circulación nacional o provincial según sea el caso, así como la distinción entre consulta popular

primarias y a las elecciones generales. Véase Cámara de Diputados, Ley 19945, cit.

59 Artículo 6 de la Ley 25.432, Consulta popular vinculante y no vinculante, cit.

60 Ibid., artículos 7-8.

61 Ibid., artículos 9-10.

62 El artículo 101.4.I del Código Electoral Nacional prevé como votos válidos aquellos emitidos mediante boleta oficializada, aun cuando tuvieren tachaduras de candidatos agregados o sustituciones. Véase Cámara de Diputados, Ley 19945, cit. 
vinculante y no vinculante; se destaca que en la no vinculante, a pesar de su carácter, el resultado mayoritario positivo obliga, si bien no a su aprobación, sí a su incorporación en la agenda legislativa. Circunstancia que incentiva la participación de la ciudadanía en la consulta con independencia de que su resultado resulte vinculante o no.

\subsection{Ecuador}

La República del Ecuador tiene un desarrollo democrático medio, ${ }^{64}$ se ubica entre los países de América Latina cuyos ciudadanos consideran que su democracia presenta grandes problemas. ${ }^{65}$ En ese país, la consulta popular es el instrumento adecuado para la participación democrática de manera directa. Se fundamenta en la Constitución de la República de Ecuador, específicamente en su artículo $103 .^{66}$

La Constitución de Ecuador, en su numeral 61.4 reconoce como derecho de las ecuatorianas y los ecuatorianos, el ser consultados. Además, el ejercicio del voto lo prevé obligatorio para los mayores de 18 años y facultativo para los mayores de 16 y menores de 18 así como para los mayores de 65 años. Asimismo, mandata que los ciudadanos participen de manera protagónica en la toma de decisiones y en la construcción de lo que la norma constitucional ecuatoriana denomina como poder ciudadano. ${ }^{67}$

En efecto, el citado texto constitucional, en la sección cuarta denominada como democracia directa, establece que dicha consulta popular será convocada por el órgano electoral por disposición de quien ocupe la titularidad del Poder Ejecutivo, en el caso del presidente de la República será el Consejo Nacional Electoral ${ }^{68}$ quien realizará la convocatoria correspondiente, sobre los asuntos que estime convenientes. ${ }^{69}$ Además, la ciudadanía tiene la potestad de solicitar la convocatoria a consulta sobre cualquier asunto, con un respaldo no menor al $5 \%$ de las personas inscritas en el registro electoral para consulta nacional y $10 \%$ para consulta local. Más aún, los ecuatorianos en el exterior también pueden accionar el citado mecanismo de participación ciudadana para asuntos de su interés con un respaldo no menor del $5 \%$ de las personas inscritas en el registro electoral de la circunscripción especial.

64 KAS, Índice de desarrollo democrático de América Latina 2016, op. cit., p. 14.

65 Corporación Latinobarómetro, Informe 2018, op. cit., p. 34.

66 Asamblea Nacional de la República del Ecuador, Constitución de la República del Ecuador, en https://www. asambleanacional.gob.ec/sites/default/files/documents/old/constitucion_de_bolsillo.pdf.

67 Ibid., artículo 95.

68 En términos de los artículos 217 y 218 de la Constitución de Ecuador, el Consejo Nacional Electoral es un órgano con autonomía administrativa, financiera y organizativa. Se conforma de cinco consejeros principales.

69 Constitución de la República del Ecuador, cit., artículo 104. La Constitución del Ecuador también prevé que la máxima autoridad de los gobiernos autónomos descentralizados, previstos en el artículo 251 del texto constitucional, con la decisión de las tres cuartas partes de sus integrantes, puede disponer que el órgano electoral convoque a consulta popular. Los temas de consulta no podrán referirse a los asuntos tributarios o a la organización política-administrativa del país. 
Ahora bien, una vez que el Consejo Nacional Electoral reciba la decisión o acepte la solicitud de los ciudadanos para la consulta popular, dentro de los quince días siguientes, convocará a la realización del citado mecanismo, mismo que deberá realizarse dentro de los sesenta días siguientes. Una vez sometido a escrutinio, se requerirá mayoría absoluta de los votos válidos para su aprobación, cuyo resultado es vinculante y de cumplimiento inmediato, destacándose que los gastos se cargarán al Presupuesto General del Estado cuando la consulta popular provenga de la disposición de quien ocupe la Presidencia de la República, en términos del artículo 147.14 de la Constitución del Ecuador, o de la solicitud de ciudadanos. ${ }^{70}$

Finalmente, de conformidad con el texto constitucional ecuatoriano y en consistencia con el modelo que prima en México y en Colombia, la Corte Constitucional emitirá dictamen previo sobre la constitucionalidad de las preguntas propuestas en la consulta popular que se solicita así como la intervención del Consejo Nacional Electoral en el trámite, este último es el que recibe directamente de los ciudadanos la referida solicitud. Otros aspectos son destacables: la rapidez con la que la consulta se lleva a cabo una vez que resulte procedente, 60 días, con efectos inmediatos en caso de obtener la mayoría absoluta de votos a favor de esta y la posibilidad de que el presidente de la República, los ciudadanos ecuatorianos residentes en el país y los residentes en el exterior puedan accionar ante el Consejo Nacional Electoral, la consulta popular.

\subsection{Perú}

La República del Perú, de conformidad con los datos de Latinobarómetro, se ubica en el último tercio de los países latinoamericanos que considerarían a la democracia como el mejor sistema de gobierno y en el primer bloque de aquellos países donde, en mayor medida, sus ciudadanos consideran que la democracia tiene grandes problemas. ${ }^{71}$ Sin embargo, ocupa el cuarto lugar en el ordenamiento regional del ranking IDD-lat 2016 con comportamientos positivos en lo concerniente al respeto de los derechos políticos, democracia de las instituciones y dimensión social. ${ }^{72}$

De hecho, la Constitución Política del Perú reconoce como derechos del ciudadano el participar en la elección, remoción o revocación de autoridades, promover iniciativas legislativas y en referéndum, ${ }^{73}$ además de reconocer que el ejercicio del voto es personal hasta los setenta años y facultativo después

$70 \quad$ Constitución de la República del Ecuador, cit., artículo 106. En el caso de la consulta que provenga de la disposición de los gobiernos autónomos descentralizados, los gastos se imputarán a su presupuesto.

71 Corporación Latinobarómetro, Informe 2018, op. cit., pp. 31-34.

72 KAS, Índice de Desarrollo Democrático de América Latina 2016, op. cit., pp. 14, 196-197.

73 Artículo 2.17. Véase Congreso de la República del Perú, Constitución Política del Perú, en http://www4.congreso.gob.pe/ntley/Imagenes/Constitu/Cons1993.pdf. 
de esa edad, previendo la neutralidad estatal en los mecanismos de participación ciudadana. ${ }^{74}$

Cabe destacar que, si bien es cierto la norma constitucional peruana no prevé expresamente, en términos nominativos, la consulta popular como mecanismo de participación ciudadana, sí prevé el referéndum, mismo que, en términos de Daniel Zovatto, ${ }^{75}$ es una de las vertientes de la consulta popular. Por lo que, para efectos de la presente aportación académica, en el caso particular de Perú, se revisará lo atiente a la figura del referéndum.

En este sentido, el artículo 32 de la Constitución del Perú prevé como materia de referéndum: las reformas totales o parciales a la Constitución; la aprobación de leyes; las ordenanzas municipales y materias relativas a descentralización. Sin embargo, no lo será: la supresión o disminución de derechos fundamentales, las normas de carácter tributario o presupuestal ni los tratados internacionales en vigor.

Por su parte, el Sistema Electoral tiene a su cargo la organización y ejecución del referéndum u otras consultas populares. ${ }^{76}$ La Oficina Nacional de Procesos Electorales organiza el proceso de referéndum y los de otros tipos de consulta popular. ${ }^{77}$ Mientras tanto, el Jurado Nacional de Elecciones, ${ }^{78}$ órgano del Sistema, fiscaliza la legalidad de la realización de los mecanismos de participación ciudadana en comento, proclama los resultados correspondientes ${ }^{79} \mathrm{y}$ sus determinaciones son definitivas e inatacables. ${ }^{80}$ De hecho, es importante destacar que el Jurado Nacional de Elecciones tiene la facultad de declarar la nulidad de un proceso de referéndum, ${ }^{81}$ bajo los criterios previstos en la Constitución de la República del Perú. ${ }^{82}$

En efecto, de la legislación peruana se destaca que en el citado mecanismo de democracia directa intervienen dos órganos: uno encargado de organizar el proceso y otro de fiscalizarlo y resolver en definitiva lo concerniente al mismo. Esta situación es similar al caso mexicano donde son el Instituto Nacional Electoral, órgano administrativo, el facultado para organizar el proceso, y el

\footnotetext{
Ibid., artículo 31.

Zovatto, "Las instituciones de la democracia directa", op. cit.

Constitución Política del Perú, cit., artículo 176.

Ibid., artículo 182

En términos de los artículos 179 y 180 del texto constitucional, el Jurado Nacional de Elecciones está conformado por 5 miembros que permanecen en el encargo por 4 años con posibilidad de reelección. El cargo es remunerado y de tiempo completo.

79 Constitución Política del Perú, cit., artículo 178.1 y 5.

$80 \quad$ Ibid., artículo 181.

81 Ibid., artículo 184.

82 De conformidad con los datos oficiales publicados por la Presidencia del Perú, hasta 2013 se habían experimentado 5 procesos de referéndum: 1919 aprobado sin datos de aprobación, 1939 con aprobación del $90 \%$, 1993 con aprobación del 52\%; 2010 con aprobación del $66 \%$ y 2013 con $51 \%$ de los votos válidos. Véase Gobierno del Perú, Plataforma digital única del Estado Peruano, en https://www.gob.pe/862-presidencia-delconsejo-de-ministros-que-es-un-referendum.
} 
Tribunal Electoral, órgano jurisdiccional especializado del Poder Judicial de la Federación, quienes resuelven en definitiva las impugnaciones derivadas del citado proceso.

\section{Propuesta de fortalecimiento institucional para la consulta ciudadana en México}

El análisis realizado a la normatividad constitucional y legal de países latinoamericanos como Uruguay, Colombia, Argentina, Ecuador y Perú permite advertir elementos que pudieran ser considerados en el diseño institucional mexicano, a partir de la consideración de las buenas prácticas, al menos a nivel de previsión normativa. Ello, sin menoscabo de reconocer que no basta con una armonía normativa desde el punto de vista formal, sino que se deben tener las condiciones materiales que permitan el ejercicio pleno de los derechos. ${ }^{83}$

En efecto, las disposiciones normativas analizadas con antelación provienen de fuente constitucional, y cada una es el resultado de diferentes momentos históricos por los que atravesaron los países y que resultaron determinantes para la realización de los cambios constitucionales y legales correspondientes. De hecho, no se puede obviar que, en términos de Roberto Gargarella, las constituciones fundacionales fueron el producto de un pacto entre élites liberales y conservadoras que organizaron una estructura de poder contramayoritaria con un diseño que evita la participación masiva de la ciudadanía en el ámbito político. ${ }^{84}$ Además, desde la "Sala de máquinas de la Constitución" se fijaron una serie de limitaciones entre las que se destacan el derecho a la participación política y un sistema político restrictivo a la participación autónoma de las mayorías. ${ }^{85}$ Sin embargo, el siglo $X X$, impulsado por diferentes movimientos sociales, ha traído el rompimiento de paradigmas en torno a la inclusión y a la participación política, lo que ha dado como resultado, la inclusión de mecanismos de democracia popular directa en los textos constitucionales. ${ }^{86}$

El caso es que, como señala Roberto Gargarella, las constituciones fueron producto de un pacto de las élites ${ }^{87}$ quienes decidieron la estructura del Estado, la

83 La presente aportación se avoca a una serie de propuestas a nivel de previsión normativa. Ello, sin desconocer que los factores que facilitan o dificultan la aplicación y eficacia de la implementación de los mecanismos de participación ciudadana, como es el caso de la consulta popular, ameritan un estudio aparte.

Cfr. Roberto Gargarella, "Apuntes sobre el Constitucionalismo Latinoamericano del siglo XIX. Una mirada histórica", en IUS Revista del Instituto de Ciencias Jurídicas de Puebla, 25 (2010), p. 32, https://www.redalyc.org/ pdf/2932/293222977002.pdf.

85 Cfr. Roberto Gargarella, "Recuperar el lugar del pueblo en la Constitución”, en Roberto Gargarella y Roberto Niembro Ortega (coords.), Constitucionalismo Progresista: retos y perspectivas. Un homenaje a Mark Tushnet, México, Universidad Nacional Autónoma de México, 2016, pp. 20-21, en https://www.ijf.cjf.gob.mx/cursosesp/2018/Octubre/Seminario_Maria_Cristina_Salmor\%C3\%A1n_Teorias_Contemporaneas/MATERIAL\%20 DE\%20LECTURA/9.\%20JUSTICIA,\%20DEMOCRACIA\%20Y\%20ESTADO \%20DE\%20DERECHO/1.\%20Autores\%20contempor\%C3\%A1neos/7.\%20Gargarella.pdf.

86 Ibid., pp. 32-33.

87 Gargarella, “Apuntes sobre el Constitucionalismo Latinoamericano del Siglo...”, op. cit. 
organización del poder y los esquemas de participación del pueblo en el ámbito público. También han sido la base para el reconocimiento y la garantía de los derechos, así como los mecanismos de control del poder. Pero, si bien dichos diseños han sido construidos por quienes tienen la legitimidad democrática e institucional para hacerlo, no siempre han atendido a los intereses populares, sino a los de la élite en el poder.

A pesar de ello, los cambios sociales y el cuestionamiento a la concentración de la toma de decisiones con exclusión de las mayorías han permitido poner en tela de juicio la forma en que se ha desarrollado el constitucionalismo en América Latina. Por lo que, el nuevo constitucionalismo latinoamericano, en términos de Correa y Luiz, apunta hacia constituciones dirigentes que invierten en instrumentos de democracia directa. ${ }^{88}$ Esto es, el nuevo constitucionalismo latinoamericano ha impulsado un cambio en el paradigma de lo que es la Constitución y cómo esta debe operar para cumplir con las funciones que les fueron otorgadas desde su creación. Desde esta perspectiva, el nuevo constitucionalismo latinoamericano ha provocado una mayor apertura de los textos constitucionales a la participación activa del pueblo en la esfera pública. Lo anterior resulta ser una encomienda difícil en virtud de que no han sido pocas las resistencias encontradas en diseños constitucionales con tendencias a ser diseñados ex professo para que la élite en el poder mantenga el control so pretexto del riesgo latente del populismo que recorre América Latina. Sobre el particular, Francisca Pou relata que el riesgo en el populismo es que los nuevos líderes no suspendan las constituciones o cesen a los jueces, sino que utilicen medios formalmente legales y constitucionales para hacerlos cómplices de sus políticas. ${ }^{89}$

En ese sentido, una de las respuestas a las circunstancias anteriores es el constitucionalismo popular, el cual intenta una mayor democratización y participación de las instituciones políticas y económicas, y recupera la relación entre derecho y política..$^{90}$ Por lo que, al buscar fortalecer el diseño institucional de la consulta popular en México a partir de la revisión de diversas disposiciones normativas constitucionales no es ajeno al interés de, en términos de Roberto Gargarella, recuperar para el pueblo un lugar central dentro de la Constitución. ${ }^{91}$

$88 \quad$ Fabio Correa Souza de Oliveira y Lenio Luiz Streck, “El nuevo constitucionalismo latinoamericano: reflexiones sobre la posibilidad de construir un derecho constitucional común", en Anuario Iberoamericano de Justicia Constitucional 18 (2014), pp. 131-138, en https://recyt.fecyt.es/index.php/AIJC/article/view/40823.

89 Francisca Pou Giménez, "Las cortes latinoamericanas en un contexto de democracias dislocadas: un análisis desde el optimismo estratégico", en Roberto Niembro O. y Sergio Verdugo (coords.), La justicia constitucional en tiempos de cambio, México, Suprema Corte de Justicia de la Nación, 2019, p. 403, en https://www.scjn.gob. $\mathrm{mx} /$ relaciones-institucionales/libro-la-justicia-constitucional-en-tiempos-de-cambio.

52490 Ana Micaela Alterio, El constitucionalismo popular y el populismo constitucional como categorías constitucionales, México, Universidad Autónoma de México, 2016, p. 68, https://archivos.juridicas.unam.mx/www/bjv/ libros/9/4257/5.pdf.

91 Gargarella, "Recuperar el lugar del pueblo en la Constitución”, op. cit., p. 55. 
Ahora bien, lo señalado permite cuestionar el diseño institucional mexicano de la consulta popular y proponer una serie de cambios que coadyuven a su fortalecimiento. Ello, en aras de otorgar una mayor apertura a los procesos de participación ciudadana y sin desconocer aquellos aspectos que resultan coincidentes. Esto es, tomando en cuenta las situaciones actuales de los países latinoamericanos revisados en torno a los distintos métodos de participación ciudadana que han previsto en sus ordenamientos normativos, es que se proponen una serie de cambios al diseño institucional de la consulta popular en México con la finalidad de que este posea algunas características que se desarrollan en líneas posteriores.

En primer término, las disposiciones normativas analizadas coadyuvan a considerar que el diseño institucional mexicano no es muy distinto en cuanto al requerimiento establecido en la legislación nacional de que las preguntas deben pasar el tamiz de constitucionalidad a cargo de la Suprema Corte de Justicia de la Nación y de que la petición debe provenir del Poder Ejecutivo o del Legislativo o bien de ciudadanos, así como el carácter vinculante de los resultados cuando una mayoría otorgue su voto a favor del Sí.

No obstante lo anterior, el diseño institucional en cita debiera ser más específico sobre el contenido y alcance de las materias de improcedencia como es el caso de los ingresos y gastos del Estado, así como la materia electoral, en virtud de que le deja un amplio margen de interpretación a la Suprema Corte de Justicia de la Nación para que esta decida sobre las implicaciones que dichas materias poseen, no obstante que estas carecen de criterios de razonabilidad para su restricción y evidencian vaguedad sobre las dimensiones o implicaciones que estas tienen. Sin embargo, en caso de que persistan tal como están las materias en el diseño actual y la Suprema Corte deba decidir si son constitucionales o no las preguntas en función de las materias sobre las cuales puede versar la consulta popular, en términos de Tushnet, esta debiera asumir una decisión basada en política, considerando esta como aquella que se centra en lo que sería mejor para la sociedad en general y no solo en principios, basada en derechos individuales. ${ }^{92}$

Aunado a lo anterior, es pertinente realizar otra modificación relativa a los temas de improcedencia previstos en el artículo 35, fracción VIII, parágrafo $3^{\circ}$ de la Constitución Política de los Estados Unidos Mexicanos, específicamente en lo que concierne al concepto de trascendencia respecto a lo que afecta o pudiera afectar a la colectividad. Es decir, si se trata de un tema trascendental se debe tomar en cuenta qué es lo trascendente, para qué colectividad y cuáles son los impactos que presenta, más allá del aspecto económico. A manera

92 Mark V. Thusnet, "The Constitution Outside the Courts: A Preliminary Inquiry", U.L.Rev. 437 (26) (1992), pas525 sim, en https://dash.harvard.edu/bitstream/handle/1/13548601/The $\% 20$ Constitution $\% 20$ Outside $\% 20$ the $\% 20$ Courts_\%20\%20A\%20Preliminary\%20Inquiry.pdf?sequence $=1$. 
de guisa, el texto constitucional prevé como tema improcedente, entre otros, las obras de infraestructura en ejecución. Sin embargo, se pueden presentar casos en los que dichas obras pudieran tener un impacto benéfico en términos económicos y, a la vez, uno o varios impactos perjudiciales en aspectos medioambientales ${ }^{93}$ y que, una vez iniciada la obra, aun ante el reclamo de la colectividad por dicho impacto medioambiental, no se pueda someter a consulta popular su ejecución a pesar de que ni siquiera para su inicio se realizó previamente la citada consulta a dicha colectividad.

Incluso, la prohibición contenida en el artículo 35, fracción VIII, parágrafo $4^{\text {o }}$ de la Carta Magna, relativa a la suspensión de la propaganda gubernamental durante el proceso de consulta popular, con las excepciones correspondientes, ${ }^{94}$ si bien obedece a que existe una disposición similar para efectos del periodo de campaña electoral, misma que tiene como objetivo la suspensión de la difusión de la propaganda gubernamental cuya ratio es el respeto al principio de imparcialidad, en el caso de la consulta popular no tiene justificación racional. Al contrario, en la medida que la ciudadanía cuente con mayor información sobre la materia de la consulta y tenga datos que le permitan incluso contrastar y verificar los resultados del trabajo que los poderes y organismos públicos realizan, contribuirá a la formación de ciudadanía y a contar con mayores elementos para una decisión a partir de un juicio crítico. Por lo que, en este caso, la propaganda gubernamental, la información institucional y la información sobre la consulta popular, no son excluyentes entre sí.

Del mismo modo, no existe una justificación racional para que el aviso de intención que presentan los ciudadanos se realice ante una de las Cámaras del Congreso de la Unión. Al contrario, debiera presentarse directamente ante el Instituto Nacional Electoral para que este proceda a la revisión del cumplimiento de los requisitos constitucionales y legales, y sea el citado organismo constitucional autónomo quien la remita a la Suprema Corte de Justicia de la Nación para efectos de la revisión de la constitucionalidad de las preguntas y de la procedibilidad de la materia. Una vez declarada la constitucionalidad por el Alto Tribunal, el Instituto Nacional Electoral podrá emitir la convocatoria a consulta popular correspondiente así como llevar a cabo los actos preparatorios, la jornada de recepción de los votos y el cómputo final de los sufragios

93 En México está aún latente la discusión sobre la factibilidad de la construcción del Tren Maya, cuyo trazo cruzará varias entidades federativas: Chiapas, Tabasco, Campeche, Yucatán y Quintana Roo. Ello, con independencia del impacto presupuestal que tendrá su construcción y su eventual operación, también se ha destacado el impacto medioambiental que dicha obra presenta.

94 Tribunal Electoral del Poder Judicial de la Federación, “Jurisprudencia 18/2011. Propaganda gubernamental. Los supuestos de excepción a que se refiere el artículo 41, base III, apartado C, de la constitución federal, deben cumplir con los principios de equidad e imparcialidad", en Gaceta de Jurisprudencia y Tesis en materia electoral, Tribunal Electoral del Poder Judicial de la Federación 9 (4) (2011), pp. 35-36, en https://www.te.gob.mx/ IUSEapp/tesisjur.aspx?idtesis=18/2011\&tpoBusqueda=S\&sWord=propaganda,gubernamental. 
cuyos resultados estarán en aptitud de ser impugnados por los ciudadanos vía Juicio para la Protección de los Derechos Político-Electorales del Ciudadano ante el Tribunal Electoral del Poder Judicial de la Federación. ${ }^{95}$ Sin embargo, si la Suprema Corte de Justicia de la Nación declara la inconstitucionalidad de las preguntas, notificará al Instituto Nacional Electoral para que este, a su vez, ordene el archivo de la solicitud correspondiente como asunto total y definitivamente concluido.

De hecho, similar circunstancia debiera ocurrir ante la petición de consulta que presente quien ocupe la titularidad del Poder Ejecutivo Federal esto es, que pudiera presentarse directamente ante el Instituto Nacional Electoral y no ante el Poder Legislativo, puesto que resulta ociosa la intervención de este último en ambos casos, máxime que el Poder Legislativo ya tuvo su intervención cuando diseñó, discutió y aprobó la ley de la materia. Por lo que no existe otra razón, más allá del intento de control político del procedimiento, para que se dé la intervención del Poder en comento. Sobre todo porque, bajo el diseño actual, la única actividad que realiza este es dar trámite a una solicitud de consulta y emitir un dictamen que incluso debe ser aprobado por el Pleno de la Cámara.

Lo expuesto con antelación resulta relevante al advertir que el diseño institucional de la consulta popular en México deja en el margen de discrecionalidad política la decisión de la mayoría de la cámara que corresponda, de aprobar o no el dictamen realizado en comisiones. Dictamen que, por cierto, posee el pronunciamiento sobre la procedencia de la consulta y de esto depende que se envíe a la Suprema Corte de Justicia de la Nación para la revisión de la constitucionalidad o inconstitucionalidad de las preguntas con relación a la materia.

De hecho, cuando la petición de consulta provenga del Poder Ejecutivo, su procedimiento debería homologarse a la propuesta presentada cuando se trate de petición de ciudadanos. Esto es, que se presente directamente ante el Instituto Nacional Electoral. Puesto que, más allá del interés del Legislativo por tener el control político de la procedencia o improcedencia de la solicitud de consulta popular, no existe razón para que, cuando se trate del Ejecutivo, tenga que aprobar el Legislativo la procedencia de esta.

Además, un aspecto por considerar es, como acontece en el modelo argentino, la implementación de la consulta no vinculante. Ello facultará a los poderes Ejecutivo y Legislativo para contar con un parámetro que les permita conocer

$95 \quad$ El Tribunal Electoral del Poder Judicial de la Federación ha señalado que en el diseño de la consulta popular deben observarse los principios relativos al derecho de voto, se organizará por una autoridad administrativa y preverá un sistema de medios de impugnación. Véase Tribunal Electoral del Poder Judicial de la Federación, “Tesis XLIX/2016. Mecanismos de democracia directa. En su diseño deben observarse los principios constitucionales para el ejercicio del derecho humano de votar", en Gaceta de Jurisprudencia y Tesis en materia electoral, Tribunal Electoral del Poder Judicial de la Federación 18 (9) (2016), pp. 96-97, en https://www.te.gob.mx/ IUSEapp/tesisjur.aspx?idtesis=XLIX/2016\&tpoBusqueda=S\&sWord=consulta, popular. 
la opinión de los ciudadanos sobre una temática en particular, misma que si bien resultaría eminentemente valorativa, su importancia como termómetro para conocer el pulso sobre el nivel de aceptación o rechazo poblacional sobre el tema por decidir no es soslayable. Esta figura, incluso, permitirá ampliar las dimensiones temáticas y fortalecerá la participación ciudadana en los procesos de decisión de los asuntos públicos además de que enriquecerá la agenda legislativa.

Incluso, como ocurre en el modelo colombiano, el diseño institucional en México debiera promover la actuación de la sociedad civil en el marco de la participación democrática, reconociéndole el derecho de participar en los procesos de democracia participativa. Sin embargo, no se desconoce que la citada circunstancia se torna aún más compleja al no contar ni siquiera con un concepto constitucionalizado de sociedad civil.

Otro aspecto por considerar es el relativo al carácter vinculatorio del resultado, puesto que este lo será cuando la mayoría de los ciudadanos que emitieron votos optaron por el "Sí" con un número diferenciado de electores que participaron en la consulta. Esto es, si bien es cierto que la Ley Federal de Consulta Popular prevé que serán vinculantes si al menos el $40 \%$ de los ciudadanos inscritos en la lista nominal electoral participaron en la consulta, la citada regla obvia que, en los procesos electorales federales, la participación de los ciudadanos es diferenciada. Esto es, hay mayor participación en aquellas elecciones en las que se eligen presidente de la República, diputados federales y senadores, que en las intermedias a nivel federal en las que solo se eligen diputados federales, ${ }^{96}$ además de considerar que, bajo la disposición constitucional actual prevista en el artículo 35, fracción VIII, parágrafo 5ํㅜ de la Constitución Política de los Estados Unidos mexicanos, se realizarán el primer domingo de agosto.

Lo expuesto con antelación permitirá fortalecer la figura de la consulta popular como mecanismo de participación que fomente la interacción del ciudadano con quien detenta el poder político y toma las decisiones públicas. Aspecto que representa un reto de proporciones considerables al tener presente que México lidera el grupo de países con bajo desarrollo democrático, presenta una debilidad constante en lo que respecta a la democracia de las instituciones, así como comportamientos negativos en democracia de los ciudadanos y democracia económica; ${ }^{97}$ además, de conformidad con los datos de Latinobarómetro 2018 tiene la segunda aprobación del gobierno más baja, solo por detrás de Brasil, ${ }^{98}$ datos que evidencian algunas de las tantas dificultades que

96 En México, en las últimas tres elecciones presidenciales, los resultados de la participación de la ciudadanía fueron los siguientes: 2006: 58,55 \%; 2012: 63,08\%; y 2018: 63,42\%; mientras que las últimas tres intermedias: 2003: 41,32 \%; 2009: 44,76 \%; 2015: 47,72 \%. Cfr. Instituto Nacional Electoral, Porcentaje de participación en elecciones de 1991 a 2015, en http://siceef.ine.mx/campc.html?p\%C3\%A1gina=1.

97 KAS, Índice de Desarrollo Democrático de América Latina 2016, op. cit., pp. 14, 22, 159.

98 Corporación Latinobarómetro, Informe 2018, op. cit., p. 44. 
enfrenta no solo la participación ciudadana en México, sino el modelo de democracia representativa que impera en el país.

\section{Conclusiones}

La regulación de la consulta popular como mecanismo de participación ciudadana en una ley específica mexicana fue un gran avance desde el punto de vista formal, aunque materialmente es y ha resultado insuficiente. Su diseño institucional, si bien posee aspectos interesantes e incluso novedosos para México, también cuenta con un entramado complejo y procesos administrativos que tornan inviable su operacionalización. Circunstancia que se agudiza ante la falta de la previsión presupuestal de recursos para su ejecución.

Aunado a lo anterior, ante los innumerables retos que vive el país y bajo la consideración de la visión del ejercicio del poder que impera en la élite política mexicana, la consulta popular representa una inmejorable oportunidad para involucrar realmente a la ciudadanía en la toma de las decisiones con trascendencia nacional y regional. Ello impedirá que continúe la práctica política imperante de llamar consulta popular a todo acto de reunión de personas en la que se les pregunta a mano alzada si están o no de acuerdo con determinado tema sin contar con mayor información que el discurso pronunciado, y que con esta práctica se pretendan legitimar las decisiones cuando dicha consulta carece de metodología y no cumple con los requisitos que el diseño institucional señala.

Además, se requiere una mayor participación de la sociedad civil -como se advirtió en el caso colombiano- en el ámbito público como revisora de la actuación de quienes ejercen el poder político. Sin embargo, es de reconocerse que se torna complejo en virtud de que aún no se cuenta ni siquiera con las implicaciones del concepto de sociedad civil en México. No obstante, ello no es limitante para que se le dé el valor que la sociedad civil juega en el fortalecimiento de la democracia.

Finalmente, las características que presenta la historia contemporánea en México: el creciente porcentaje de abstencionismo; la falta de confianza en las instituciones; la dificultad del Estado para garantizar el ejercicio de los derechos humanos; las escasas y, por tanto, insuficientes condiciones para la participación ciudadana en la toma de las decisiones públicas; la opacidad en el ejercicio del poder político; la existencia de una élite partidocrática y la falta de resultados contundentes en el combate a la corrupción institucional, demandan más y mejores espacios y condiciones para la interacción entre quien detenta el poder político y los ciudadanos, a fin de permitir el fortalecimiento de la democracia representativa y la democracia participativa. 


\section{Bibliografía}

Alterio, Ana Micaela, El constitucionalismo popular y el populismo constitucional como categorías constitucionales, México, Universidad Autónoma de México, 2016, en https://archivos.juridicas.unam.mx/www/bjv/libros/9/4257/5.pdf, fecha de consulta: 20 de julio de 2020.

Asamblea Nacional de la República del Ecuador, Constitución de la República del Ecuador, en https://www.asambleanacional.gob.ec/sites/default/files/ documents/old/constitucion_de_bolsillo.pdf, fecha de consulta: 16 de abril de 2020.

Bovero, Michelangelo, "Los adjetivos de la democracia", en Conferencias Magistrales 2 (temas de la democracia), México, Instituto Nacional Electoral, 2016, en https://www.ine.mx/wp-content/uploads/2019/04/CM_02_Bovero.pdf, fecha de consulta: 4 de febrero de 2020.

Cámara de Diputados, Constitución Política de los Estados Unidos Mexicanos, en http://www.diputados.gob.mx/LeyesBiblio/index.htm, fecha de consulta: 23 de julio de 2020.

Cámara de Diputados, Ley Federal de Consulta Popular, en http://www.diputados.gob.mx/LeyesBiblio/pdf/LFCPo.pdf, fecha de consulta: 23 de julio de 2020 .

Cámara de Diputados, Ley 19945 Código Electoral Nacional, en https://www. diputados.gov.ar/export/hcdn/secparl/dgral_info_parlamentaria/dip/archivos/Ley_19945_TA.pdf, fecha de consulta: 14 de abril de 2020.

Camou, Antonio, "Gobernabilidad y democracia", en Cuadernos de divulgación de la cultura democrática 6, 2 ed., México, Instituto Nacional Electoral, 2019, en https://www.ine.mx/wp-content/uploads/2020/02/cuaderno_06.pdf, fecha de consulta: 9 de mayo de 2020.

Congreso de Colombia, Ley 134 de 1994 por la cual se dictan normas sobre Mecanismos de Participación Ciudadana, en https://www.iidh.ed.cr/capel2016/ media/1111/ley-134-1994-mecanismos-de-participaci\%C3\%B3n-ciudadana. pdf, fecha de consulta: 14 de abril de 2020.

Congreso de la Nación Argentina, Constitución Nacional, en https://www.congreso.gob.ar/constitucionNacional.php, fecha de consulta: 14 de abril de 2020 y 15 de abril de 2020.

Congreso de la Nación Argentina, Ley 25.432, Consulta Popular Vinculante y No Vinculante, en https://www.argentina.gob.ar/normativa/nacional/ley25432-67518/actualizacion, fecha de consulta: 14 de abril de 2020. 
Congreso de la República del Perú, Constitución Política del Perú, en http:// www4.congreso.gob.pe/ntley/Imagenes/Constitu/Cons1993.pdf, fecha de consulta: 16 de abril de 2020.

Corporación Latinobarómetro, Informe 2018, Santiago de Chile, 2018, en https:// www.latinobarometro.org/lat.jsp, fecha de consulta: 14 de abril de 2020.

Correa Souza de Oliveira, Fabio y Lenio Luiz Streck, "El nuevo constitucionalismo latinoamericano: reflexiones sobre la posibilidad de construir un derecho constitucional común", en Anuario Iberoamericano de Justicia Constitucional (18) (2014), en https://recyt.fecyt.es/index.php/AIJC/article/ view/40823, fecha de consulta: 20 de julio de 2020.

Corte Constitucional de la República de Colombia, Constitución Política de Colombia 1991, en https://www.corteconstitucional.gov.co/inicio/Constitucion\%20politica\%20de\%20Colombia.pdf, fecha de consulta: 14 de abril de 2020.

Gargarella, Roberto, "Apuntes sobre el constitucionalismo latinoamericano del siglo XIX. Una mirada histórica", en IUS Revista del Instituto de Ciencias Jurídicas de Puebla (25) (2010), en https://www.redalyc.org/ pdf/2932/293222977002.pdf, fecha de consulta: 20 de julio de 2020.

Gargarella, Roberto, "Recuperar el lugar del pueblo en la Constitución", en Roberto Gargarella y Roberto Niembro Ortega (coords.), Constitucionalismo progresista: retos y perspectivas. Un homenaje a Mark Tushnet, México, Universidad Nacional Autónoma de México, 2016, en https:// www.ijf.cjf.gob.mx/cursosesp/2018/Octubre/Seminario_Maria_Cristina_ Salmor\%C3\%A1n_Teorias_Contemporaneas/MATERIAL\%20DE\%20LECTURA/9.\%20JUSTICIA,\%20DEMOCRACIA\%20Y\%20ESTADO\%20DE\%20 DERECHO/1.\%20Autores\%20contempor\%C3\%A1neos/7.\%20Gargarella. pdf, fecha de consulta: 20 de julio de 2020 .

Gobierno del Perú, Plataforma digital única del Estado Peruano, en https://www. gob.pe/862-presidencia-del-consejo-de-ministros-que-es-un-referendum, fecha de consulta: 16 de abril de 2020.

Habermas, Jürgen, Teoría de la acción comunicativa I, 4 ed., Bogotá, Taurus, 1999, en https://zoonpolitikonmx.files.wordpress.com/2014/03/habermasjurgen-teoria-de-la-accion-comunicativa-i.pdf, fecha de consulta: 18 de abril de 2020.

Instituto Nacional Electoral, Estadísticas del Padrón Electoral y Lista Nominal de Electores, en https://listanominal.ine.mx/ESTADISTICAS/index.php, fecha de consulta: 18 de abril de 2020. 
Instituto Interamericano de Derechos Humanos, Ley 134 de 1994 (mayo 31) por la cual se dictan normas sobre Mecanismos de Participación Ciudadana, en https:// www.iidh.ed.cr/capel2016/media/1111/ley-134-1994-mecanismos-departicipaci\%C3\%B3n-ciudadana.pdf, fecha de consulta: 17 de abril de 2020 .

Instituto Nacional Electoral, Porcentaje de participación en elecciones de 1991 a 2015, en http://siceef.ine.mx/campc.html?p\%C3\%A1gina=1, fecha de consulta: 18 de abril de 2020 .

Konrad Adenauer Stiftung, Índice de Desarrollo Democrático de América Latina 2016, Uruguay, Fundación Konrad Adenauer Argentina y Polilat, 2016, en http://idd-lat.org/2016/downloads/idd-lat-2016.pdf?nocache=7687652837, fecha de consulta: 13 de abril de 2020.

Lerner, Pablo, "Sobre armonización, derecho comparado y la relación entre ambos", en Boletín Mexicano de Derecho Comparado XXXVII (111) (2004), en https://revistas.juridicas.unam.mx/index.php/derecho-comparado/article/ view/3807, fecha de consulta: 20 de julio de 2020.

Morán Torres, Enoc Francisco, Descifrando la partidocracia mexicana, México, Porrúa, 2017.

Organización de los Estados Americanos (OEA), Convención Americana sobre Derechos Humanos, en https://www.oas.org/dil/esp/tratados_b-32_convencion_americana_sobre_derechos_humanos.htm, fecha de consulta: 15 de abril de 2020.

Ortega y Gasset, José, La rebelión de las masas, 3 ed., México, Editorial Tomos, 2016.

Pegoraro, Lucio, "El método comparativo. Un shortcut para comprender el mundo", en Lucio Pegoraro y Angelo Rinella (dirs.), Derecho constitucional comparado, t. 2, vol. A, Argentina, Astrea, 2018.

Poder Legislativo de la República Oriental del Uruguay, Constitución de la República, en https://parlamento.gub.uy/documentosyleyes/constitucion, fecha de consulta: 13 de abril de 2020.

Pou Giménez, Francisca, "Las cortes latinoamericanas en un contexto de democracias dislocadas: un análisis desde el optimismo estratégico", en Roberto Niembro O. y Sergio Verdugo (coords.), La justicia constitucional en tiempos de cambio, México, Suprema Corte de Justicia de la Nación, 2019, en https://www.scjn.gob.mx/relaciones-institucionales/libro-la-justicia-constitucional-en-tiempos-de-cambio, fecha de consulta: 24 de julio de 2020.

Prud'homme, Jean François, "Consulta Popular y democracia directa", en Cuadernos de divulgación de la cultura democrática 15, 2 ed., México, Instituto Nacional Electoral, 2019, en https://www.ine.mx/wp-content/uploads/2020/02/ cuaderno_15.pdf, fecha de consulta: 10 de abril de 2020. 
Sartori, Giovanni, ¿Qué es la democracia?, México, Editorial Patria, trad. de Miguel Ángel González Rodríguez, 1993.

Suprema Corte de Justicia de la Nación, Consulta a trámite prevista en el párrafo segundo de la fracción II del artículo 14 de la Ley Orgánica del Poder Judicial de la Federación 1/2014, 27 de marzo de 2014, en http://www2.scjn.gob. $\mathrm{mx} /$ ConsultaTematica/PaginasPub/DetallePub.aspx?AsuntoID=161925, fecha de consulta: 7 de abril de 2020 .

Suprema Corte de Justicia de la Nación, Revisión de constitucionalidad de la materia de Consulta Popular 2/2014, 29 de octubre de 2014, en http://www2.scjn.gob.mx/ConsultaTematica/PaginasPub/DetallePub. aspx?AsuntoID=172299, fecha de consulta: 7 de abril de 2020.

Suprema Corte de Justicia de la Nación, Revisión de constitucionalidad de la materia de Consulta Popular 3/2014, 30 de octubre de 2014, en http://www2.scjn.gob.mx/ConsultaTematica/PaginasPub/DetallePub. aspx?AsuntoID=172300, fecha de consulta: 7 de abril de 2020.

Suprema Corte de Justicia de la Nación, Revisión de constitucionalidad de la materia de Consulta Popular 4/2014, 3 de noviembre de 2014, en http://www2.scjn.gob.mx/ConsultaTematica/PaginasPub/DetallePub. aspx?AsuntoID=172628, fecha de consulta: 7 de abril de 2020.

Tribunal Electoral del Poder Judicial de la Federación, “Jurisprudencia 18/2011. Propaganda gubernamental. Los supuestos de excepción a que se refiere el artículo 41, base III, apartado C, de la Constitución federal, deben cumplir con los principios de equidad e imparcialidad", en Gaceta de Jurisprudencia y Tesis en materia electoral, Tribunal Electoral del Poder Judicial de la Federación 9 (4) (2011), en https://www.te.gob.mx/IUSEapp/tesisjur.aspx?idte sis=18/2011\&tpoBusqueda=S\&sWord=propaganda,gubernamental, fecha de consulta: 20 de julio de 2020.

Tribunal Electoral del Poder Judicial de la Federación, “Tesis XLIX/2016. Mecanismos de democracia directa. En su diseño deben observarse los principios constitucionales para el ejercicio del derecho humano de votar", en Gaceta de Jurisprudencia y Tesis en materia electoral, Tribunal Electoral del Poder Judicial de la Federación 18 (9) (2016), en https://www.te.gob.mx/ IUSEapp/tesisjur.aspx?idtesis=XLIX/2016\&tpoBusqueda=S\&sWord=cons ulta,popular, fecha de consulta: 20 de julio de 2020.

Thusnet, Mark V., "The constitution outside the courts: A preliminary inquiry", en U.L.Rev. 437 (26) (1992), en https://dash.harvard.edu/bitstream/handle/1/13548601/The $\% 20$ Constitution $\% 20$ Outside $\% 20$ the $\% 20$ Courts_\%20 $\% 20 \mathrm{~A} \% 20$ Preliminary\%20Inquiry.pdf?sequence=1, fecha de consulta: 22 de julio de 2020. 
Zovatto, Daniel, "Las instituciones de la democracia directa", en Alicia Lassidini et al. (comps.), Democracia en movimiento: mecanismos de democracia directa y participativa en América Latina, México, Universidad Nacional Autónoma de México, Centro de Investigaciones sobre Democracia Directa e Instituto Internacional para la Democracia y la Asistencia Electoral, 2014, en https://archivos.juridicas.unam.mx/www/bjv/libros/8/3717/3.pdf, fecha de consulta: 13 de abril de 2020 . 